Revista Temas Socio Jurídicos

Vol. $36 \mathrm{~N}^{\circ} 73$ Julio - Diciembre de 2017

pp. $141-152$

ISSN 0120-8578

ISSN electrónico: 2590-8901

\title{
RESPONSABILIDADES POLÍTICO-ELEITORAIS, O IMPEACHMENT, A IMPROBIDADE E A DEMAGOGIA
}

\author{
Rilke Rithcliff Pierre Branco* \\ Recibido: Agosto 23 de 2017 \\ Aprobado: Septiembre 27 de 2017
}

\section{RESUMO}

Este artículo se centra en los instrumentos operativos de nuevos procedimientos para determinar las responsabilidades políticas y electorales a la luz de un análisis de la Justicia Constitucional de Brasil, con una reflexión sobre las acciones y propuestas contra la demagogia y la improbidad de los mandatarios.

Palavras-chave: Justiça Constitucional, impeachment, demagogia político-eleitoral.

\section{LAS RESPONSABILIDADES POLÍTICO-ELEITORAIS, EL IMPE ACHMENT, LA IMPROBIDAD Y DEMAGOGIA}

\section{RESUMEN}

Este artículo se centra en los instrumentos operativos de nuevos procedimientos para determinar las responsabilidades políticas y

* Profesor, alumno del Curso de Doctorado de Derecho en la Universidad Federal de Buenos Aires (UBA), MBA en Ciencias Políticas, MBA en Seguridad laboral y Medio Ambiente, es aún especialista en Derecho Constitucional, Derecho Administrativo, Derecho Civil, Consultoría Empresarial, Derecho Tributario, Derecho Procesal, Derecho Deportivo, Gestión Pública y Legislación, con postgrado aún en Enseñanza en Historia, Geografía y Sustentabilidad. 
electorales a la luz de un análisis de la Justicia Constitucional de Brasil, con una reflexión sobre las acciones y propuestas contra la demagogia y la improbidad de los mandatarios.

Palabras clave: Justicia constitucional, acusación, demagogia políticaelectora

\title{
POLITICAL-ELECTORAL RESPONSIBILITIES, IMPEACHMENT, IMPROBITY AND DEMAGOGY
}

\begin{abstract}
This article focuses on the instruments of Constitutional Court's procedures to determine the political and electoral responsibilities, emphasizing a brief reflection on the actions and proposals against the demagoguery of candidates for public elective positions in the face of Brazilian systems, activities and government.
\end{abstract}

Keyswords: Constitutional justice, impeachment, political-electoral demagoguery.

\section{INTRODUÇÃO:}

O recente processamento do impeachment da Presidente da República no Brasil, em 31/08/2016, fez emergir a ideia de Justiça Constitucional como problema da investigação que impõe ao Direito e à Ciência Política tratar com prioridade, sobretudo a par dos rumos que se deve dar na interpretação de preceitos e institutos da democracia.

Com uma breve análise teórica, pragmática e científica dos fatos jurídicos e das responsabilidades políticas que decorrem dos processos eleitorais e governamentais naquele país, a hipótese examina que a deposição de mandatários populares precisa aperfeiçoar-se. O sistema legal vigente precisa vir a contemplar também outras questões importantes que embalam a atividade político-partidária, tais como a repressão à prática de improbidades e à demagogia de candidatos a vagas na Administração Pública.

Com consultas legislativas, métodos descritivos e intuitivos, o estudo propõe a criação de ações judiciais específicas nesta área e uma reflexão crítica realista para as mudanças de mentalidades que os sistemas políticos atuais propositadamente rejeitam. 


\section{DOS ILÍCITOS COMUNS E DOS CRIMES ELEITORAIS SEGUNDO A LEGISLAÇÃO BRASILEIRA}

Para elidir conflitos, dirimir dúvidas, designar prerrogativas, direitos e os deveres básicos da cidadania e das ações político-eleitorais, o princípio da legalidade normativa expressa é insculpido no átrio constitucional e se oferece para regular cláusulas, para resolver problemas e espraiar fatos de amplas repercussões jurídicas.

Neste eixo valorativo, as relações político-eleitorais se expõem às sanções do Estado frente às perpetrações das violações legais prescritas, atingindo, pois, a população, candidatos, eleitores, agentes, servidores e dirigentes governamentais.

Sem embargo da autonomia e dos poderes conferidos aos partidos na democracia, há uma rígida disciplina que repousa sobre o controle dos personagens que atuam na vida política e eleitoral, cujas transgressões se sujeitam a procedimentos de cunho administrativo ou jurisdicional. No sistema brasileiro, dentre estas infringências, uma das mais relevantes concerne ao dever de prestação de contas à Justiça Eleitoral e à prática de probidade na execução orçamentária do Estado, que abarcam, obviamente, a estrita atenção às rotinas financeiras e notas contábeis por parte do gestor público.

A envergadura jurídico-atributiva destas normas declina as penalidades pertinentes às respectivas infrações legais. Assim, no Brasil, por exemplo, a irregularidade no recebimento ou no manejo de recursos torna passível a suspensão das cotas do fundo partidário e até a ação de cancelamento de registro do partido político.

Outro campo propício à prática de ilícitos se refere à administração de recursos da campanha eleitoral. A arrecadação de doações, o uso e o gasto de receitas, sob esta rubrica, submetem-se mesmo a uma forte fiscalização. A Justiça Eleitoral, ao seu turno, cobra, individualmente de cada candidato ou dos órgãos partidários, uma responsabilidade autônoma que, só por exceção, é solidária. Neste diapasão, o Código Eleitoral brasileiro nomina os tipos delituosos e as Resoluções do Tribunal Superior Eleitoral servem para punir os titulares das ofensas aos bens tutelados pela regra penal.

No Brasil, os financiamentos de campanha, que se tornaram proibidos para as pessoas jurídicas depois da "explosão" de denúncias de práticas de “caixa-2", são impugnáveis por todos os partidos e podem ensejar o 
cancelamento da candidatura, a cassação do diploma, a perda do cargo ou do mandato dos seus responsáveis. Penas menos drásticas são aplicáveis, no entanto, às hipóteses de propagandas eleitorais ilícitas que são classificáveis em irregulares e extemporâneas, havendo ainda outras modalidades criminosas, passíveis de penas pecuniárias, de apreensão ou prisão.

\section{DOS ABUSOS DE PODER NOS PROCESSOS POLÍTICO- ELEITORAIS}

Os abusos de poder dizem respeito mais aos ilícitos relacionados a fraudes e à prática de corrupção eleitoral do que às infrações tipicamente administrativas. Já as consequências desses desvios repercutem na esfera do Direito Penal, que são, didaticamente, divididos em duas ordens de motivações: a econômica e a política.

Neste passo, os casos, por instância, de despesas não autorizadas ou o emprego de recursos de origem espúria, além de encetarem a desaprovação das contas do partido ou do candidato junto à Justiça Eleitoral, em tese, enquadram-se como abuso de poder econômico, sujeito à comprovação mediante um procedimento dentro dos ditames da devida legalidade. Nesta mesma linha, o financiamento ilícito de campanhas eleitorais ilícitos, as doações não contabilizadas, o excesso de limites, o desvio de gastos ou o uso indevido de sobras de dinheiro dos comitês financeiros dos partidos ou dos candidatos podem configurar abusos do poder econômico e, assim, ensejarem a aplicação de multas e a cassação do diploma outorgado, sem prejuízo da tomada de providências cabíveis ante os indícios de irregularidades ou rejeição das contas pela Justiça, se assim for o fato objeto de representação do Ministério Público Eleitoral.

Já os abusos do poder político diferem desses tipos multicriteriais e se encostam no conceito determinado e nominado de sufrágio ilegal. A doação, a oferta, a promessa ou a entrega de bem ao eleitor, pelo partido ou candidato, com o fim de obter voto, preveem, assim, multa e cassação do registro e do diploma, à luz do art. 41-A da Lei no 9.504/1997. Já a doação comum ou a cessão de servidores, móveis e imóveis no ano de eleições, bem como a presença do candidato em eventos artísticos, na inauguração de obras públicas, em pronunciamento em cadeia de rádio ou TV nos 3 (três) meses anteriores eleições, e, ainda, outras hipóteses de nomeação, remoção ou demissão de pessoal neste período, assim como o aumento salarial de servidores 6 (seis) meses antes até a posse do candidato, também conferem a possibilidade de que os titulares dos direitos subjetivos eleitorais contestem estes atos no âmbito judicial. 144 
Para coibir esses ilícitos, a legislação eleitoral alberga as seguintes ações que possuem caráter específico quanto à competência e matéria: a impugnação ao registro de candidatura (AIRC), a investigação judicial eleitoral (AIJE), a impugnação de mandato eletivo (AIME), os recursos contra diplomação (art. 262, CE), o direito de resposta (rito sumaríssimo), além da ação contra propaganda e a corrupção, dentre outras. Inexiste, porém, ação judicial específica contra a demagogia político-eleitoral.

\section{DA PROPOSTA DA AÇÃO DE IMPROBIDADE CONTRAA DEMAGOGIA POLÍTICO-ELEITORAL}

Assunto recente e emblemático no Brasil atine ao julgamento da chapa que usou "dinheiro sujo", oriundo de esquemas criminosos. A tendência seria reconhecer-se a corrupção e decretar-se a "inidoneidade das contas" que maculou a campanha eletiva dos Presidentes Dilma e Temer, que, contudo, foram absolvidos pelo Tribunal Superior Eleitoral brasileiro em apertada e polêmica votação no julgamento do dia 09/06/2017.

À vista dos inúmeros princípios ínsitos na redoma constitucional, as normas de repressão aos ilícitos políticos e eleitorais, embora já se encontram bem emolduradas e complementadas em uma legislação que delimita a responsabilidade dos ocupantes de cargos eletivos, no plano penal, civil e administrativo, deixam, todavia, a desejar.

Exceção seria o tratamento emprestado à improbidade administrativa que, no Brasil, estriba-se na Lei $\mathrm{n}^{\circ} 8.429 / 92$, ao punir o enriquecimento ilícito dos agentes públicos na administração pública direta, indireta ou fundacional. $\mathrm{O}$ aludido diploma visa, pois, à sanção do sujeito que, agindo de má fé, provoca lesão ao patrimônio público e que, assim, locupleta-se ilicitamente às custas do Poder Público. Apenas a ação ou omissão permeada com desonestidade ou com deslealdade é que caracteriza a improbidade administrativa e há possibilidade de afastamento cautelar do agente púbico suspeito, por ordem judicial (art. 20). Mas nada disso se aplica aos "agentes políticos".

No quadrante da Teoria do Abuso de Direito, a ideia de improbidade funda-se, portanto, em parênteses éticos e morais que permitem a ilação de que os atos passíveis de constrição legal devem originar-se de um juízo razoável de propositada desídia, inépcia ou incompetência de um gestor público. A administração ruinosa e prejudicial atrai, enfim, o selo da improbidade administrativa, mas não depõe contra a politicagem. A gravidade da penalização por força da improbidade é tão expressiva que o agente ímprobo pode até ficar inelegível com “(...) a suspensão dos 
direitos políticos, a perda da função pública, a indisponibilidade dos bens e o ressarcimento ao erário, na forma e gradação previstas em lei, sem prejuízo da ação penal cabível", segundo a inteligência do $\S 4^{\circ}$ do art. 37 da CF, e das Leis Complementares 64/90 e 135/10.

Sem embargo deste rígido quadro punitivo, as responsabilidades jurídicas dos ocupantes de cargos eletivos não estão definidas ao todo, sendo omissas, quando se colige, porém, as desconformidades e as demagogias praticadas dos mandatários; antes, durante e após a disputa eleitoral. Na prática, a legislação brasileira, e talvez de muitas democracias consolidadas, são condescendentes com este tipo de "estelionato eleitoral".

Nos processos políticos-eleitorais, a falta dos denodos morais, individuais ou partidários, as promessas, as doações e os objetos frutos de campanhas demagógicas, que traem a confiança do eleitorado nos candidatos, sobretudo após a ocupação de postos no Poder Público, não recebem uma proteção jurídica séria com a correspondente penalidade à altura. O desdém pela ética do "jogo político", as firulas e os sofismas verbais dos participantes dos pleitos eleitorais não disfarçam o afã verdadeiro de muitos que objetivam apenas obter vantagens materiais pessoais, em detrimento da probidade e da incolumidade do Estado de Direito Constitucional na devida condução da res publica.

Ora, neste panorama, esta ação de responsabilidade político-eleitoral se preconizaria como uma providência inovadora e que teria seu fundamento legal em uma norma cogente, de ordem pública e de incidência erga omnes, voltada ao resgate da probidade e da moralidade de todas as etapas dos processos de seleção dos candidatos a cargos eletivos, a ser apurada e ao final julgada pelo órgão judiciário competente.

Esta actio, estribada em provas de que a propaganda política do candidato e o seu marketing da campanha não se comunicaram com o primado da realidade, seria recebida com a demonstração da conduta do legitimado passivo da efetiva disparidade entre o que o candidato se comprometeu a fazer, na fase eleitoral, e o que, efetivamente, ele efetuou na fase pós-eleitoral, ao exercer seus primeiros anos de mandato. A espécie contra esse tipo de estelionato se nominaria, pois, "ação de improbidade contra a demagogia político-eleitoral", a ser afeiçoada pela doutrina e transformada em lei.

A ideia é alçar a propaganda e a promessa social do candidato à condição de um veículo realmente sério do seu escopo ideológico, que não 146 
poderia, pois, desvirtuar-se de seus compromissos com a conquista ou a conservação do poder, sob pena de sujeitar-se a esta ação. Com a "qualificação real" da propaganda eleitoral, que é uma ferramenta democrática, o candidato sofreria, então, sanções legais se se provasse que a simpatia de adeptos a seu projeto eletivo foi fruto de uso artifícios demagógicos.

Ora, a demagogia político-eleitoral não condiz com os postulados éticouniversais da Ciência Política e, por isso, não podem mais ser tolerados os meios e as linguagens dissimuladas de candidatos que induzem o povo a concluir aptidões, máscaras ou benefícios inexistentes de pessoas que postulam ou se habilitam ao exercício de função pública, máxime se se levantam depois suas características e reais más intenções quando do exercício do poder. Neste contexto, as promoções pessoais, auferidas por manobras demagógicas, em certas hipóteses, seriam suscetíveis de aferição e posterior julgamento através dos procedimentos comuns de representação.

O combate à demagogia político-eleitoral não se confunde, mutatis mutandis, com o art. 96 da Lei Eleitoral Geral brasileira, cujo rito poderia ser aproveitado. Este dispositivo, todavia, acarreta apenas uma pena pecuniária e determina a cessação da conduta irregular, mas poderia ser empregada para condenar outros malfeitos, em respeito ao eleitorado que é o destinatário final do engodo do candidato. A demagogia políticoeleitoral não deveria, pois, ser tratada como simples erro de campanha, desvio de comunicação social ou abuso de propaganda eleitoral, e sim como um método que, além de irregular e criminoso, comina ao seu titular uma "responsabilidade específica", sujeitando o infrator a outras restrições dos direitos relativos ao exercício das cidadanias, seja ele candidato. ou já mandatário eleito.

Ipso facto, as subversões demagógicas são artifícios que levam o eleitor a equívocos ou a condicionamentos psicológicos que infectam a sua opção consciente de vontade, interferindo, assim, na legitimidade e na respeitabilidade do voto da cidadania.

Confirmada a tese de que o marketing eleitoral cria sim na opinião pública "estados mentais, emocionais ou passionais", sob esta égide, a divulgação de promessas ou de propagandas demagógicas, que não são cumpridas pelo candidato eleito, ofende não só os incisos previstos no art. 243 do Código Eleitoral, como também expurga o interesse da coletividade e, em particular, do eleitor, que é o alvo maior da democracia. 
A liberdade de manifestação do candidato não pode, de modo algum, usurpar a seriedade e a higidez do processo eleitoral e governamental ${ }^{2}$, nem muito menos afetar a credibilidade que resta apostada no voto do eleitor, com o qual o mandatário ou o representante político devem guardar respeito, harmonia e fidelidade.

Como a captação ideológica do povo depende da sua identificação com o conteúdo programático exposto pelo candidato, esta simbiose políticoeleitoral não pode ser desfeita após a conquista do mandato eletivo nas urnas e no cargo.

Consistindo a propaganda e o marketing na força motriz do moderno processo eleitoral, na medida em que é o método de maior aproximação entre o candidato e seu público-alvo, assim, o candidato que incorrer em demagogias eleitorais para vencer a disputa, ou que corroborá-las durante seu mandato eletivo, responderia a uma ação judicial específica de improbidade político-eleitoral.

A finalidade é apenar o cidadão passivo, ou seja, o candidato eleito que decai, titubeia, esquece ou que não cumpre suas promessas de campanha, abusando e exorbitando, de forma dolosa, de seus deveres éticos e morais, malversando, enfim, os princípios da probidade pública, da dignidade e do politismo de uma Administração.

Com estas ponderações, a ação de improbidade político-eleitoral não seria uma consideração de qualquer falha técnica de gestão ou de deficiência de desempenho de um múnus público, mas sim um procedimento legal de correção, para averiguar se a pessoa eleita agiu em desapreço à "moralidade" pública, dentro da expectativa criada pela população em torno de sua plataforma e programas de campanha. É que a admissão de um candidato no processo eleitoral reside na ideia objetiva de que o preenchimento de um cargo eletivo pressupõe um regime de atuação em nome da supremacia pública do Estado. A campanha ou atividade político-eleitoral, portanto, não se volta para fins de facilitação de direitos ilegítimos ou ilegais, próprios ou de terceiros.

A exibição dos planos e promessas políticas, portanto, seriam catalogadas pela Justiça Eleitoral previamente e subordinaria à avaliação da idoneidade e da honestidade da conduta pública do representante eletivo por meio desta ação em que seriam assegurados os axiomas democráticos do contraditório e da ampla defesa, para a depuração moral dos candidatos e o enobrecimento das atividades e funções políticas. 


\section{DOS CRIMES DE RESPONSABILIDADE, DO IMPEACHMENT E DO RECALL NORTE-AMERICANO}

As objeções aos mandatários públicos e a algumas autoridades da República decorrem dos mais diversos motivos, sendo, atualmente, o impeachment uma fórmula encontrada pelo Direito para afastar os dignitários do Poder Executivo, Legislativo ou Judiciário dos seus cargos, em face de denúncias ou acusações descritas como crime de responsabilidade, que nada mais são do que infrações políticoadministrativas.

A acusação que lastreia o impeachment é de natureza fática e constitucional, que segue um procedimento administrativo-jurídico próprio, de índole penal especial, com o afã de proceder à destituição do agente político do seu cargo ou função.

Equivalendo, na prática, a uma impugnação judicial que pode culminar com cassação do mandatário político, trata-se de mecanismo de remoção pós eleitoral derivado da Inglaterra e que foi logo acatado por outras nações democráticas para apenar infrações de natureza políticoadministrativa atribuídas ao agente político.

Distinguindo-se do abberufungsrecht, o Direito Anglo-Saxão, ao seu turno, desenvolveu um processo de iniciativa do eleitorado, que busca a remoção ou a extinção do mandato do representante político que se revele um gestor público inapto, desatencioso ou desidioso, o chamado recallpolítico.

De se ver que, enquanto o impeachment depende de um órgão constitucional para instaurar um juízo de censura frente a uma grave violação, confirmada por uma Casa Legislativa, o recallpolítico provém da insatisfação institucional do eleitor contra condutas havidas como inadequadas, ímprobas, incompetentes ou inoperantes por parte do mandatário público. Diferente do impeachment, por se tratar de um ato simples e puramente político do eleitorado que rechaça o administrador, o recallpolítico é uma "reavaliação" popular que retira o mandato político sem uma motivação específica.

Sem acatar o instituto do recall, o art. 85 da Constituição Federal brasileira admitiu apenas o impeachment para definir os crimes de responsabilidade capazes de afastar o representante popular. O rito desse processo é regulado pela Lei 1.079/50 e, no caso de denúncia contra o Chefe do Poder Executivo nacional brasileiro, a admissibilidade da acusação cabe à votação de $2 / 3$ (dois terços) dos representantes da 
Câmara dos Deputados e se exige igual quórum do Senado para a condenação do Presidente, que, além da perda do mandato, fica inelegível pelo prazo de 8 (oito) anos.

Na historiografia recente do brasil, apesar de sua renúncia, o Presidente Fernando Collor de Mello sofreu em 1992 um processo de impeachment que lhe rendeu a suspensão dos direitos políticos; em 2016, foi a vez da Presidente Dilma Roussef, que se viu envolvida em denúncias de ilegalidades e fraudes fiscais, tendo sido afastada do poder, a exemplo do que se sucedeu na Venezuela com Carlos Rodrígues (1993), no Equador com Abdala Ortiz (1997) e com Fernando Lugo no Paraguai (2012). Em 2017, o Presidente brasileiro Temer manteve-se no cargo após a admissibilidade de ação penal ter sido negada por votação da Câmara dos Deputados contra o seu impeachment. Já os Estados Unidos assinalaram a destituição de dois Presidentes por impeachment, Andrew Johnson, em 1868; e Richard Nixon; este que renunciou antes ao seu mandato em 1974 em virtude do megaescândalo conhecido como o Watergate. Como se vê, nos regimes presidencialistas, o impeachment tem sido pivô de muitas críticas e controvérsias, ainda que seu provimento se condicione à manifestação político do Poder Legislativo que, normalmente, é composto por parlamentares que, favoráveis ao governo, lançam mão de manobras e expedientes imorais, como a oferta de cargos, emendas e outras negociatas que depõem contra a probidade e a democracia. Em Ciência Política, a experiência prova que, mais justo e menos traumático que o impeachment, o recall é um instrumento legítimo para cassar representantes e governos. Entretanto, em nenhuma das experiências brasileiras aqui citadas pode-se falar que houve "golpe" ou ruptura constitucional, como, lamentavelmente, alardeia o grupo que foi destituído do poder.

\section{CONCLUSÕES}

Este artigo fez uma breve reflexão crítica e científica sobre a atuação da Justiça Política e de suas teias constitucionais, legais e institucionais que constroem as fisionomias do exercício das atribuições estatais e da cidadania no Brasil. Através de uma abordagem dos fatos e das estruturas do arcabouço público atual, percebe-se que urge aperfeiçoar não só o sistema partidário-eleitoral, mas também alguns instrumentos do controle jurídico dos governos, suas formas da representação e suas fontes políticas.

Sendo fato que os povos democráticos latinos seguem uma ética ideológica, baseada em parâmetros ditados por uma disputa quase intestina do poder, que favorece ordinariamente a ocorrência de abusos voltados aos benefícios de grupos dominantes, ao invés da realização de 150 
planos e de projetos populares ou nacionais de desenvolvimento, o estudo pontuou a possibilidade de instalação de novos mecanismos para uma participação cívica mais ativa e vocacionada ao aprimoramento destes processos.

Já no campo das responsabilidades jurídicas, ao lado das ilicitudes comuns, foram analisados en passant alguns crimes de repercussão no orbe eleitoral e enfatizada a identificação das práticas de abusos de poder nos procedimentos político-eleitorais que justificam, além dos remédios legais já existentes contra as tipologias assinaladas, a sugestão acadêmica de instituir-se uma ação judicial específica de improbidade contra a demagogia político-eleitoral, a ser definida por lei quanto ao seu cabimento, rito, admissibilidade, procedimentos de defesa e lista de legitimado, mas com a finalidade clara de evitar e punir os estelionatos eletivos e as fraudes de atos governamentais.

Os contornos legais e as experiências do recall do Direito anglo-saxão e dos impeachments também foram confrontados frente aos delitos de responsabilidade, salientando-se a premência da dignidade da atuação política e a defesa da probidade pública, como valores essenciais da atividade político-eleitoral e da democracia.

A implementação de uma Justiça Política neoconstitucional, centrada, pois, na enumeração, quantitativa e qualitativa, dos objetivos filosóficopragmáticos da tutela dos direitos políticos do povo e de defesa do eleitorado não prescindem, assim, de uma maior sofisticação legal, sobretudo para evitar a privatização dos poderes públicos, o gigantismo das investidas autoritárias e os golpes dos "estelionatários políticos". A ideia é transformar o cidadão de hoje em uma figura mais respeitada, cerebral e participativa; um fiscalizador ativo das condutas dos seus mandatários e dos representantes do Estado, na luta contra os desperdícios e as irresponsabilidades de governantes desonestos.

O recente caso brasileiro do dia 31/08/2016 que culminou com a destituição da Presidente Dilma Roussef pelo Senado brasileiro não pode ser considerado como um golpe, senão como uma fórmula constitucional e legal previamente descrita e aplicada para a solução de um impasse grave que esta nação enfrentou nestes últimos tempos, graças aos desastres fiscais e às demagogias político-eleitorais que foram, finalmente, rechaçados através de um legítimo processo de impeachment da citada mandatária. Por decisão do Poder Legislativo, o Presidente Temer por pouco não foi afastado de suas funções, após ter sido denunciado por corrupção passiva perante a Justiça brasileira. 
Os abusos de poder e os desvios das finalidades públicas, assim decididos, democrática e soberanamente, pelo Poder Legislativo brasileiro, ante as contrariedades a preceitos legais e constitucionais por parte da mais alta autoridade da República, reforçam, portanto, o caráter vivo e dinâmico da Ciência Política, comprometida que está com resoluções humanistas e com o burilamento dos processos, das temáticas e das garantias atinentes à qualidade dos governos, ao bem-estar e à confiança da população.

Neste sentido, para remediar ou atenuar os conflitos, as crises e as consequências destas convulsões político-sociais, nesta seara, o politismo, e não a "politicagem" pode reverter descalabros administrativos e os "jogos político-eleitorais" nocivos à moralidade do Estado, reoxigenando um país rumo ao seu crescimento.

O balizamento técnico e os revestimentos científicos das cosmodemocracias precisam, enfim, ampliar as reações programáticas e de inteligência para que operem uma firme e vital mudança das nossas paragens históricas e culturais, cabendo aos estudiosos prosseguirem na pesquisa da equidade das leis e na saúde dos seus institutos.

No palco de uma traumática disputa pelo poder, que se agrava por força de colapsos econômicos no continente e pelo mau gerenciamento de verbas públicas, que ganham proporções cada vez mais graves para os povos latino-americanos, a democracia necessita de ferramentas institucionais que possam corrigir distorções ou avançar na solução das situações de várias problemáticas individuais e coletivas que afetam, historicamente, os seus governos e os seus instáveis regimes de governo.

Unir sabedoria e justiça na Política, na Economia e no Direito configurase, pois, a Revolução Humanista do século XXI; significa a esperança de um futuro melhor.

\section{REFERÊNCIAS BIBLIOGRÁFICAS}

BONAVIDES, Paulo. Ciências Políticas. São Paulo: Malheiros, 2009, pp. 12 e segus.

AZAMBUjA, Darcy. Introdução à Ciência Política. 5. ed. Rio de Janeiro: Globo, 1985, p. 341. 